Journal of Animal

Ecology 2007

76, 946-956
(C) 2007 The Authors. Journal compilation (C) 2007 British Ecological Society

\title{
Understanding contributions of cohort effects to growth rates of fluctuating populations
}

\author{
HEIKO U. WITTMER *†, ROGER A. POWELL $\$$ and CAROLYN M. KING \\ * Ecology Group, Institute of Natural Resources, Massey University, Private Bag 11222, Palmerston North, \\ New Zealand; †Wildlife, Fish \& Conservation Biology, University of California, One Shields Ave., Davis, California \\ 95616-8751 USA; \$Department of Zoology, North Carolina State University, Raleigh, North Carolina 27695-7617 \\ USA; and §Centre for Biodiversity and Ecological Research, Department of Biological Sciences, Waikato University, \\ Private Bag 3105, Hamilton, New Zealand
}

\begin{abstract}
Summary
1. Understanding contributions of cohort effects to variation in population growth of fluctuating populations is of great interest in evolutionary biology and may be critical in contributing towards wildlife and conservation management. Cohort-specific contributions to population growth can be evaluated using age-specific matrix models and associated elasticity analyses.

2. We developed age-specific matrix models for naturally fluctuating populations of stoats Mustela erminea in New Zealand beech forests. Dynamics and productivity of stoat populations in this environment are related to the 3-5 year masting cycle of beech trees and consequent effects on the abundance of rodents.

3. The finite rate of increase $(\lambda)$ of stoat populations in New Zealand beech forests varied substantially, from 1.98 during seedfall years to 0.58 during post-seedfall years. Predicted mean growth rates for stoat populations in continuous 3-, 4- or 5-year cycles are $0 \cdot 85,1 \cdot 00$ and $1 \cdot 13$. The variation in population growth was a consequence of high reproductive success of females during seedfall years combined with low survival and fertility of females of the post-seedfall cohort.

4. Variation in population growth was consistently more sensitive to changes in survival rates both when each matrix was evaluated in isolation and when matrices were linked into cycles. Relative contributions to variation in population growth from survival and fertility, especially in 0-1-year-old stoats, also depend on the year of the cycle and the number of transitional years before a new cycle is initiated.

5. Consequently, management strategies aimed at reducing stoat populations that may be best during one phase of the beech seedfall cycle may not be the most efficient during other phases of the cycle. We suggest that management strategies based on elasticities of vital rates need to consider how population growth rates vary so as to meet appropriate economic and conservation targets.
\end{abstract}

Key-words: elasticity, environmental variation, life-history strategies, matrix models, vital rates.

Journal of Animal Ecology (2007) 76, 946-956

doi: 10.1111/j.1365-2656.2007.01274.x

\section{Introduction}

Populations are characterized by variability among individuals, correlated both with their intrinsic qualities and with environmental effects on their performance

Correspondence: Heiko U. Wittmer, Wildlife, Fish \& Conservation Biology, University of California, One Shields Ave., Davis, California 95616-8751, USA. Tel.: +1(530)754 7640 . E-mail: huwittmer@ucdavis.edu
(Pfister \& Stevens 2003). In variable environments, previous environmental conditions can influence lifehistory traits and performance of individuals at future times (Lindstrom 1999; Beckerman et al. 2002). The relationship between birth environment and these delayed life-history effects can lead to cohort effects (Beckerman et al. 2003). Cohort effects are populationlevel responses to common environmental conditions within generations, and have been described across a wide range of taxa including mammals and birds (e.g. 
Cohorts and growth rates in fluctuating populations

(C) 2007 The Authors. Journal compilation (C) 2007 British Ecological Society, Journal of Animal Ecology, 76, 946-956
Albon, Clutton-Brock \& Guiness 1987; Lindstrom 1999). Variation in fitness among cohorts has recently prompted increased attention to the differential contribution of successive cohorts to the dynamics of fluctuating populations (Beckerman et al. 2002).

Details about how cohort effects influence population dynamics can be particularly important where models are used to guide management. For example, age-structured matrix models and associated elasticity analyses have been used to develop conservation strategies for endangered populations as well as control methods for invasive and pest species (e.g. Shea \& Kelly 1998; Benton \& Grant 1999). Because elasticity analyses quantify the relative importance of a given matrix element to population growth rate, they generally provide more information than do sensitivity analyses (Caswell 2000), suggesting that management should focus on those demographic parameters with the largest elasticity values (e.g. Caswell 2000; De Kroon, Groenendael \& Ehrlén 2000). None the less, variation in cohort-specific vital rates due to temporal variation in the environment may result in population growth rates that vary over a series of good and bad years. This variation in growth rates may yield matrices with elasticity values that also vary from one year to the next. Additionally, substantial variation in environmental conditions may generate variation in survival and fecundity that can be correlated (Beckerman et al. 2002; Coulson, Gaillard \& FestaBianchet 2005). Both temporal variation in population growth rates and covariation between vital rates can substantially affect elasticity values and thus the decision as to which vital rate should be targeted as well as the preferred timing of management.

The European stoat Mustela erminea (Linnaeus), a small $(<350 \mathrm{~g})$, fast-moving and wide-ranging (home ranges to 200 ha) mustelid (Murphy \& Dowding 1994), was first introduced to New Zealand in 1884, and is now widespread and common. In forests of southern beech Nothofagus spp., the dynamics and productivity of stoat populations are related to the 3-5 year masting cycle of the beeches and its consequent effects on the abundance of introduced feral house mice Mus musculus (Linnaeus). Temporary population irruptions of stoats usually follow the heavy beech seed falls that stimulate an equally short-lived increase of mice (Choquenot \& Ruscoe 2000), and introduced ship rats Rattus rattus (Linnaeus) (Blackwell, Potter \& Minot 2001; Dilks et al. 2003). The cycle set off by each seed fall is complete within 18-24 months, and is followed by a period of relative scarcity of mice, rats and stoats. King (2002) hypothesized that the observed fluctuations of stoats in New Zealand beech forests are driven by cohort effects as a consequence of low survival rates of first-year stoats in post-seedfall years.

The temporary irruptions of stoats are often associated with severe predation on endangered native birds and bats of New Zealand beech forests (e.g. O'Donnell \& Phillipson 1996; Wilson et al. 1998; Basse, McLennan \& Wake 1999; Dilks et al. 2003; Pryde, O’Donnell \&
Barker 2005). In managed populations of stoats, the period of greatest risk to native fauna is during the summer of the irruption, because the additional predation by the large number of young stoats is not buffered by the extra rodents (White \& King 2006). If a substantial proportion of this large cohort of stoats survives into the following year, as in unmanaged populations, the period of high risk may continue over winter and possibly into the next summer (Murphy $\&$ Dowding 1994). To offset the impact of stoats on endangered native fauna in beech forests, it is therefore essential to develop effective control strategies that anticipate and prevent post-seedfall irruptions of stoats.

Our objective was to understand the contributions of successive cohorts to variation in population growth rates of fluctuating populations of stoats in New Zealand beech forests. We developed four different matrices, one each for stoat populations living through: (1) seedfall years when mice are increasing; (2) post-seedfall years when both mice and stoats are at peak numbers; (3) crash years when mice populations have declined to low densities; and (4) transitional years before the next seedfall year, when both mice and stoats are at low densities. We then linked the matrices into cycles and investigated how the relative importance of different vital rates changed as the cycle progressed. This approach allowed us to study the effects of group-level variability on the annual growth rates of populations in temporally variable environments, and to contrast a sequence of scenarios with different population growth rates. Understanding the importance of different cohorts is critical for understanding the dynamics of fluctuating populations, to develop effective conservation strategies for fluctuating populations of endangered species, and to control invasive or pest species.

\section{Methods}

\section{STUDY AREAS, SAMPLING DESIGN AND SEEDFALL RECORDS}

We used data from studies on stoat biology collected at three different sites (Eglinton Valley, Hollyford Valley and Craigieburn) in the South Island of New Zealand between 1971 and 1978 [see King (1983) for a description of physical attributes and vegetation communities of the three study areas]. All three stoat samples were collected from relatively undisturbed forests dominated by or including Nothofagus species, as part of a systematic monitoring programme collecting data on seed fall (eight seed trays at 50-m intervals), mice (36 trap stations at 50-m intervals) and stoats (14-50 traps at 400-m intervals) along different lengths of the same transect line. The data used to estimate population parameters of stoats were derived from a year-round removal-sampling regime using steel (Fenn) traps. The total sample included in our analyses was 793 individuals (371 females/422 males).

Removal sampling can potentially affect population dynamics, particularly under intensive trapping regimes, 


\section{8}

H. U. Wittmer,

R. A. Powell \&

C.M. King in both space and time. Stoat population dynamics in our study, however, were probably not influenced significantly by the removal sampling, for three reasons. First, the density of stoats of all ages and both sexes in summer, the critical period of any given year, was overwhelmingly affected by the productivity of adult females (not their density) in the preceding spring (late August to November), and was therefore determined before the summer sample was taken (Powell \& King 1997). Second, the mortality imposed by kill-trapping at 400-m spacing was small compared with the very high natural mortality of stoats. Age-structure and density indices from kill-trapped samples in the post-seedfall summer of 1976/77 did not differ from those derived from live traps at the same locations in the post-seedfall summer of 1979/80 (King \& McMillan 1982; Powell \& King 1997). Third, the rate of increase of each sampled population was unlikely to be affected by our sampling regime, because our traps were widely spaced and operated intermittently. The 173 stoats removed from November 1974 to March 1976 probably accounted for less than half of the total population then available in each large ( $\geq 1000$ ha) study area (King 1980). In general, removal trapping must be more intensive than in our study to affect the population growth rate of stoats (McDonald \& Harris 2002).

The three-stage correlation between seed fall, mice and stoats is generally reliable (Ruscoe \& Murphy 2005), so a heavy seed fall involving all local beech species is usually taken as a warning of a widespread irruption of stoats in the following summer (O'Donnell \& Phillipson 1996). Partial seed falls have less predictable and more patchy results. We used all available data on the distribution and intensity of beech seed fall in our study areas including known size of seeds and total annual seed fall (King 1983; Allen \& Platt 1990) to reconstruct from seedfall records the history of variation in food supplies for stoats in our study areas.

\section{PARAMETERS AND MODEL CONSTRUCTION}

\section{Age structure}

As in previous models of stoat populations (e.g. McDonald \& Harris 2002) we restricted our model to females. The age in years of all females over 6 months old in our study was estimated from canine cementum annuli (Powell \& King 1997). Young female stoats reach puberty at less than 2 months of age (King \& Moody 1982) but must survive past 1 year to achieve any reproductive success. Based on our data, we grouped females into three age classes: first-year (0-1 year), second-year (1-2 years) and old (a composite age class including all females $>2$ years old). Old females comprise a small proportion of the total population (Eglinton Valley $=$ $0 \cdot 11$, Hollyford Valley $=0 \cdot 16$, Craigieburn $=0 \cdot 02$ ), and by grouping them in one class we avoided the problems of estimating vital rates from small samples.

In southern New Zealand young stoats are born in October (King \& Moody 1982) and first venture out of the nest in late November. Practically no young of the year are caught before mid December, so age structures derived from this material exclude all individuals that died before the age of independent dispersal (2-3 months). Thus, our data for first-year cohorts were collected from early summer (i.e. December) onwards. We defined a biological year as commencing in spring, on 1 October, and classified each birth year according to its phase of the beech mast cycle. Most of the beech seeds fall in March-June, so, for example, the cohort of 1976/77 was born in the post-seedfall year commencing October 1976, following the seed fall of March-June 1976.

\section{Survival probabilities}

Age-specific survival probabilities $\left(p_{x}\right)$ were estimated from the proportion of stoats known to have been alive at age $x$ that survived to age $x+1$, using Caughley's (1977) Method 4, which requires neither marked individuals nor a stable population size. We calculated $p_{x}$ separately for all cohorts, resulting in a mean and variance (SE) for each estimated survival probability. As our data were insufficient to detect real variation in survival among seedfall, crash and transitional years, we modelled only survival probabilities for post-seedfall and other years (Table 1).

\section{Fecundity and fertility}

Fecundity (ovulation rate) is much easier to measure in stoats than fertility (litter size). Female stoats mate after they become sexually mature at 2 months of age
(C) 2007 The Authors. Journal compilation (C) 2007 British Ecological Society, Journal of Animal Ecology, 76, 946-956
Table 1. Vital rates of stoat populations $( \pm \mathrm{SE})$ in New Zealand used in the matrix models simulating four different years of a typical beech mast cycle

\begin{tabular}{|c|c|c|c|c|}
\hline Model parameters & Seedfall years & Post-seedfall years & Crash years & Transitional years \\
\hline Fertility $\mathrm{F}^{*}+t$ & $4 \cdot 40( \pm 1 \cdot 35)$ & $1.64( \pm 0.62)$ & $0 \cdot 75( \pm 0.58)$ & $3.95( \pm 1 \cdot 28)$ \\
\hline Survival age $0-1 \S$ & $0.35( \pm 0.09)$ & $0.08( \pm 0.02)$ & $0.35( \pm 0.09)$ & $0.35( \pm 0.09)$ \\
\hline Survival age $1-2 \S$ & $0.46( \pm 0.09)$ & $0 \cdot 30( \pm 0 \cdot 18)$ & $0 \cdot 46( \pm 0.09)$ & $0 \cdot 46( \pm 0 \cdot 09)$ \\
\hline Survival > 2 years & $0.50( \pm 0.04)$ & $0.50( \pm 0.04)$ & $0.50( \pm 0.04)$ & $0 \cdot 50( \pm 0 \cdot 04)$ \\
\hline
\end{tabular}

*King (1981)

$\uparrow$ King \& Moody (1982).

\$King et al. (2003b).

§Powell \& King (1997) (reanalysed). 
Cohorts and growth rates in fluctuating populations

(C) 2007 The Authors. Journal compilation (C) 2007 British Ecological Society, Journal of Animal Ecology, 76, 946-956 before leaving the nest, at about the same time as the post-partum (re)matings of their mothers. Virtually all newborn females caught in New Zealand have mated by the end of November (King \& Moody 1982), and, like adults, carry the small corpora lutea of delay for the next 9-10 months, which means that fecundity rates can be estimated from females of all ages. Female stoats have no way to anticipate (sensu Boutin et al. 2006) the optimum match between litter size and food supply next spring. Consequently, ovulation rates are high every year (mean 7·4-10.6 ova per female, range 3-20; King \& Powell 2007). Fertility rates are difficult to determine directly because nests are hard to find. However, as the probability of first capture does not vary with age or sex (King et al. 2003a), recruitment can be approximated from the ratio of young to adult females in summer samples (King et al. 2003b).

Variation in recruitment for stoats is primarily correlated with food supply, not age (Powell \& King 1997), and is determined by a combination of intrauterine mortality (failure to implant, resorption of implanted embryos) and nestling mortality (King et al. 2003b). When prey are abundant during the period from implantation of blastocysts in August (at the end of a seedfall year) until the emergence of young stoats from the nest in mid December (early in the post-seedfall year), there is little to no pre-independence mortality, and recruitment rates in January can approach the physiological maximum (King 1981; King et al. 2003b). During the following 2 years, recruitment is limited, for different reasons. Females mated in post-seedfall years have high fecundity but low fertility, because prey reduction during the period of delayed implantation leads to low implantation rates and high nestling mortality; females mated in crash years have low fecundity (King 1981). During transitional years, low nestling mortality and reduced intraspecific competition improve recruitment rates (Powell \& King 1997). Mean and variance of estimated recruitment rates over the duration of a 4-year beech mast cycle are summarized in Table 1.

\section{MATRIX MODELS}

Matrix models have been used extensively to evaluate the dynamics of age-structured populations (Caswell 1989). Assuming annual birth-pulse reproduction, we used survival and fertility data for each of the three age classes to parameterize the following population projection matrix $(A)$ :

$A=\left[\begin{array}{ccc}F_{1} * p_{1} & F_{2} * p_{2} & F_{3} * p_{3} \\ p_{1} & 0 & 0 \\ 0 & p_{2} & p_{3}\end{array}\right]$,

where $F_{x}$ equals the age-specific fertility, $p_{X}$ equals the age-specific survival probabilities and the matrix columns represent the age classes. In these matrices, the surviving females produce new, independent offspring at the same time that they all change age classes on
1 October the following year (that is, our matrices begin just after the birth pulse each year; Caswell 1989; Case 2000 , p. 60, Method 2). However, while our matrices are based on biological years, they actually predict parameters of stoat populations in December just after newborn stoats become independent because fertility rates have been adjusted to account for nestling mortality. The finite rate of increase $(\lambda)$ of these matrices is given by the dominant eigenvalue of the projection matrix A, and the stable age distribution (w) corresponds to the right eigenvector (Caswell 1989). The left eigenvector yields the reproductive value $(v)$, and represents the contribution of each age class to the total population (Tuljapurkar \& Caswell 1997). Reproductive values have been normalized to 1 , so represent relative contributions of each age class.

The sensitivity of a population's growth rate to a change in matrix element $a_{i j}$ is defined as the partial derivative of $\lambda$ with respect to $a_{i j}$ (Caswell 1989):

$\frac{\partial \lambda}{\partial a_{i j}}=\frac{v_{i} w_{j}}{<w, v>}$

eqn 1

where $v_{i}$ and $w_{j}$ refer to the $i$ th and $j$ th elements of the age-specific reproductive value and stable age distribution vectors, respectively, and where $\langle w, v\rangle$ is the scalar product of $w$ and $v$ (i.e. $\langle w, v\rangle=v_{1} w_{1}+v_{2} w_{2}+\ldots+v_{n} w_{n}$ ). The elasticity, $e_{i j}$, of $\lambda$ to element $a_{i j}$ is the sensitivity rescaled to account for the magnitude of both $\lambda$ and the matrix element (Caswell 1989):

$e_{i j}=\frac{a_{i j}}{\lambda} \frac{\partial \lambda}{\partial a_{i j}}=\frac{\partial \log \lambda}{\partial \log a_{i j}}$

eqn 2

Thus, elasticities predict the proportional change in growth rate given a proportional, small change in a matrix element, while all other elements remain constant. Elasticities of the reproduction elements of our matrices also contain aspects of survival; consequently, we calculated lower level elasticities, which express the underlying elasticity of a vital rate $x$ (Caswell 1989):

$\frac{x}{\lambda} \frac{\partial \lambda}{\partial x}=\frac{x}{\lambda} \sum_{i, j} \frac{\partial \lambda}{\partial a_{i j}} \frac{\partial a_{i j}}{\partial x}$

eqn 3

These lower level elasticities predict more accurately than elasticities of matrix elements or than sensitivities the potential effectiveness of management strategies targeting different vital rates (Mills, Doak \& Wisdom 1999).

We generated four matrices, corresponding to conditions encountered during the successive years of a typical beech mast cycle in New Zealand. The first matrix represented vital rates typical of beech seedfall years. The second matrix represented vital rates observed during post-seedfall years (i.e. during a stoat irruption), while the third and fourth matrices used vital rates typically observed during crash and transitional years, respectively. 
950

H.U. Wittmer,

R. A. Powell \&

C.M. King
C 2007 The Authors.

Journal compilation (C) 2007 British

Ecological Society, Journal of Animal Ecology, 76, 946-956

Table 2. Lambda, stable age distribution and normalized reproductive values (with $95 \%$ confidence intervals) for stoats of three age classes subject to removal sampling during a typical beech cycle in New Zealand, derived from population projection matrices

\begin{tabular}{|c|c|c|c|c|}
\hline & Seedfall years & Post-seedfall years & Crash years & Transitional years \\
\hline Lambda & $1 \cdot 98(0 \cdot 96-3 \cdot 37)$ & $0.58(0.47-0.73)$ & $0 \cdot 76(0 \cdot 46-1 \cdot 23)$ & $1 \cdot 85(0 \cdot 88-3 \cdot 22)$ \\
\hline \multicolumn{5}{|c|}{ Age distribution } \\
\hline $0-1$ year & $0 \cdot 80(0 \cdot 61-0 \cdot 88)$ & $0.59(0 \cdot 30-0 \cdot 74)$ & $0 \cdot 37(0 \cdot 01-0 \cdot 66)$ & $0 \cdot 78(0 \cdot 58-0 \cdot 87)$ \\
\hline $1-2$ year & $0 \cdot 14(0 \cdot 10-0 \cdot 21)$ & $0 \cdot 08(0 \cdot 03-0 \cdot 13)$ & $0 \cdot 16(0 \cdot 01-0 \cdot 26)$ & $0 \cdot 15(0 \cdot 10-0 \cdot 22)$ \\
\hline$>2$ year & $0 \cdot 06(0 \cdot 02-0 \cdot 17)$ & $0 \cdot 33(0 \cdot 16-0 \cdot 65)$ & $0 \cdot 47(0 \cdot 13-0 \cdot 98)$ & $0 \cdot 07(0 \cdot 02-0 \cdot 19)$ \\
\hline \multicolumn{5}{|c|}{ Reproductive value } \\
\hline $0-1$ year & $0 \cdot 26(0 \cdot 15-0 \cdot 36)$ & $0 \cdot 06(0 \cdot 00-0 \cdot 10)$ & $0 \cdot 25(0 \cdot 14-0 \cdot 35)$ & $0 \cdot 26(0 \cdot 14-0 \cdot 36)$ \\
\hline $1-2$ year & $0 \cdot 35(0 \cdot 25-0 \cdot 45)$ & $0 \cdot 32(0 \cdot 02-0 \cdot 52)$ & $0 \cdot 36(0 \cdot 27-0 \cdot 43)$ & $0 \cdot 35(0 \cdot 25-0 \cdot 45)$ \\
\hline$>2$ year & $0 \cdot 39(0 \cdot 30-0 \cdot 49)$ & $0.62(0.40-0.98)$ & $0.39(0.30-0.51)$ & $0 \cdot 39(0 \cdot 30-0 \cdot 50)$ \\
\hline
\end{tabular}

We then combined the matrices in 2-5-year cycles and projected populations over multiple cycles. Because each matrix acts on a population vector derived from another matrix, age distribution never stabilizes over the whole cycle. We thus projected populations until the age distribution stabilized for each phase of the cycle and then calculated the annualized, rate of increase exhibited across a cycle.

We used periodic matrix models (Caswell \& Trevisan 1994) to derive elasticity values for the combination of the four cohorts, varying the number of crash years from 0 to 1 and transitional years from 0 to 2 to simulate typical variations in masting of New Zealand beech forests. Elasticity values for periodic matrices are calculated for each of the individual cohorts over a whole beech mast cycle. Thus, they yield information on the importance of vital rates in any specified year for the population growth over the entire cycle. All matrix analyses were performed using Microsoft Excel and the Excel Add-In PopTools (Hood 2005).

\section{STOCHASTICITY AND ENVIRONMENTAL VARIATION}

We incorporated stochasticity into our matrix model following Wisdom \& Mills (1997). To account for uncertainty in our estimates of vital rates, we modified the spreadsheet model to sample both fertility and adult survival from a specified probability distribution that reflected temporal variation for a specified vital rate. Values for vital rates were selected using the Excel function NORMINV (probability,mean,standard_dev), where 'probability' is a uniform random number from 0 to 1 (selected using the function RAND()), and 'mean' and 'standard_dev' are the estimate and standard error of each vital rate (Table 1). Each set of randomly selected vital rates for the population was then used to construct a time-invariant matrix population model. We repeated the procedure 1000 times, thus resampling from the probability distribution of each vital rate for each replicate.

Individual population projection matrices are density-independent, i.e. vital rates do not vary as a consequence of variation in population density within distinct years. Instead, density dependence is included in our analysis by linking matrices into cycles where variation in vital rates among years reflects variation in population density throughout the population cycle. Statistical analyses were conducted using the percentile method (Efron \& Tibshirani 1993).

\section{Results}

\section{POPULATION GROWTH}

Our matrices document the cycle of increase and decrease in stoat populations driven by the beech mast cycle. The finite rates of increase are positive during seedfall years $(\lambda=1.98)$ and transitional years $(\lambda=$ $1 \cdot 85)$, and negative during post-seedfall $(\lambda=0 \cdot 58)$ and crash years $(\lambda=0 \cdot 76)$ (Table 2). Rates of increase are significantly lower between post-seedfall and both seedfall and transitional years (Table 2). Linking individual matrices into cycles shows that the overall $\lambda$ depends on the number of transitional years in the cycle. Projected populations decline during a 2-year cycle with only seedfall and post-seedfall years $(\lambda=0 \cdot 89)$ and during a 3 -year cycle with no transitional year $(\lambda=0 \cdot 85)$. Projected populations are stable $(\lambda=1 \cdot 00)$ during a cycle with one transitional year, and increase $(\lambda=1 \cdot 13)$ during cycles with two transitional years. Populations linked into cycles of random length (25 years) and projected for 100 years are, essentially, stable $(\lambda=0 \cdot 99)$.

Figure 1 compares the observed density indices of stoats in our three study areas against the predicted density indices derived from arranging our matrices into the actual seedfall cycles experienced at each site. The figure verifies that our model captures the dynamics of the populations used to derive the parameters.

\section{AGE DISTRIBUTION AND REPRODUCTIVE VALUES}

The mean age of all stoats in this sample was 15 months ( $n=793$; median $=4 ; 5-95 \%$ range $=2-40)$. The upper $95 \%$ range interval of 40 months (or 3.33 years) suggests that few wild stoats in our managed populations live longer than the duration of a single beech mast cycle of average length. 

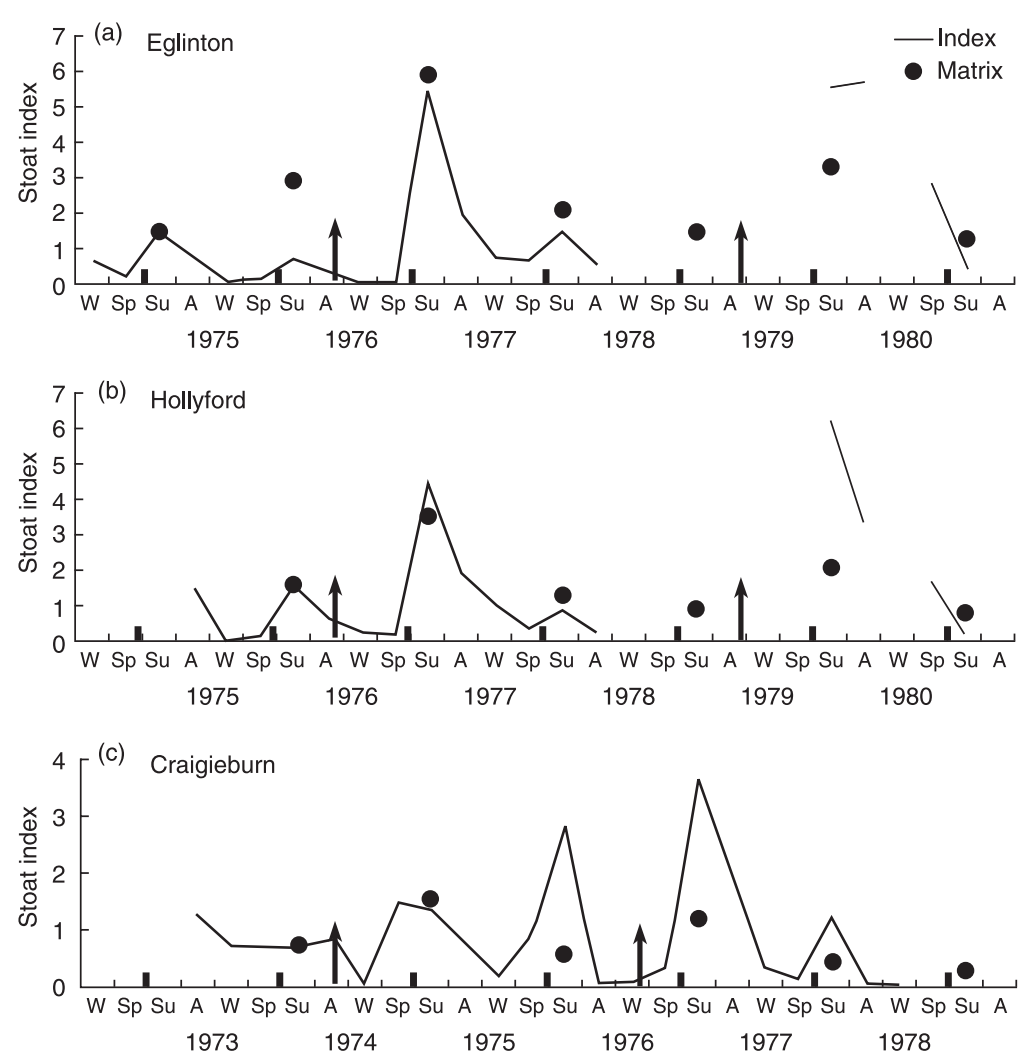

Fig. 1. Observed density indices for stoats in (a) Eglinton Valley, (b) Hollyford Valley, and (c) Craigieburn (King 1983) compared with those predicted by our matrices. Predictions were generated by using the first summer population index and age distribution for each site in the first population vector and then applying our matrices in the order of the beech cycle at each site. Population index values are shown by thin lines; predictions from our models are shown as black dots with arrows indicating seedfall years. After the first year, index values are highly correlated with predicted values (Pearson correlation coefficient $=0 \cdot 67, P=0 \cdot 02$ ).

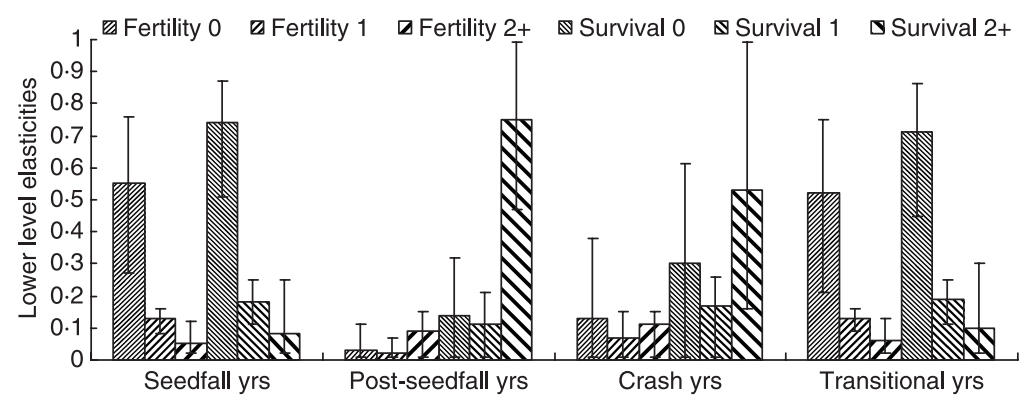

Fig. 2. Lower level elasticities ( $\pm 95 \%$ confidence intervals) for vital rates for stoats estimated from four different matrices during a typical beech mast cycle of stoat in New Zealand Nothofagus forests.

(C) 2007 The Authors. Journal compilation (C) 2007 British Ecological Society, Journal of Animal Ecology, 76, 946-956
Estimated stable age distributions vary with the phase of the beech cycle (Table 2). First-year females of the post-seedfall cohort comprise $59 \%$ of all females of the peak population of stoats in the post-seedfall year, but contribute only about $6 \%$ to the subsequent cohort. Hence, even though these females are born during the period of peak prey availability, their reproductive value is significantly lower than that of female stoats born during all other years (i.e. the $95 \%$ confidence intervals around this estimate do not overlap with those of other years). During all years, the average reproductive values of $>2$ years old females are larger than those of younger ones (Table 2).

\section{ELASTICITY ESTIMATES FOR INDIVIDUAL YEARS}

Our elasticity analyses indicate which age-specific vital rates are most critical to the overall population growth rate. During all years, $\lambda$ is most sensitive to changes in survival rates (Fig. 2). During seedfall and transitional years, $\lambda$ is more sensitive to changes in survival of first-year females. By contrast, in post-seedfall and crash years $\lambda$ is most sensitive to changes in survival probabilities of $>2$-year-old females. Elasticities of fertility are significant for first-year females only during seedfall and transitional years.

Confidence intervals on elasticities suggest that potential error in the values, caused by inaccurate estimation of vital rates, will not affect our results. During seedfall and transitional years, confidence intervals are largest for elasticities of survival and fertility of firstyear females (Fig. 2). By contrast, confidence intervals are largest for elasticities of survival of first-year and $>2$-year-old females during post-seedfall and crash years. However, elasticities of these vital rates are so large that they would still be the most significant vital rates even if they were greatly affected by sampling error.

\section{ELASTICITY ESTIMATES FOR THE ENTIRE CYCLE}

When we link matrices into cycles, elasticities for vital rates in each phase of the cycle change depending on what stage of the cycle the present year is (Figs 3-5). In Figs 3-5, each row starts at a different phase of the stoat population cycle and shows the elasticities for vital rates at future phases of cycle. The elasticities shown for each future phase of the cycle quantify the impact of the vital rates in that year on future dynamics of the population. For example, for a 3-year cycle when the present year is a seedfall year, no vital rates stand out as being particularly important to variation in $\lambda$. Survival of all age classes in the seedfall and crash years is modestly more important than fertility while survival of 1-2-year-old and older stoats is most important during forthcoming post-seedfall years (Fig. 3). In contrast, for a 3-year cycle when the present year is a post-seedfall year, survival and fertility of 0 -1-year-old stoats is most important in the forthcoming transitional and seedfall years. Yet, for the present post-seedfall year, no vital rate stands out as important.

In all scenarios (i.e. 3-, 4- and 5-year cycles), variation in population growth is consistently most sensitive to changes in survival rates. With increasing numbers of transitional years, survival of 0 -1-year-old stoats becomes more important when compared with survival of older 

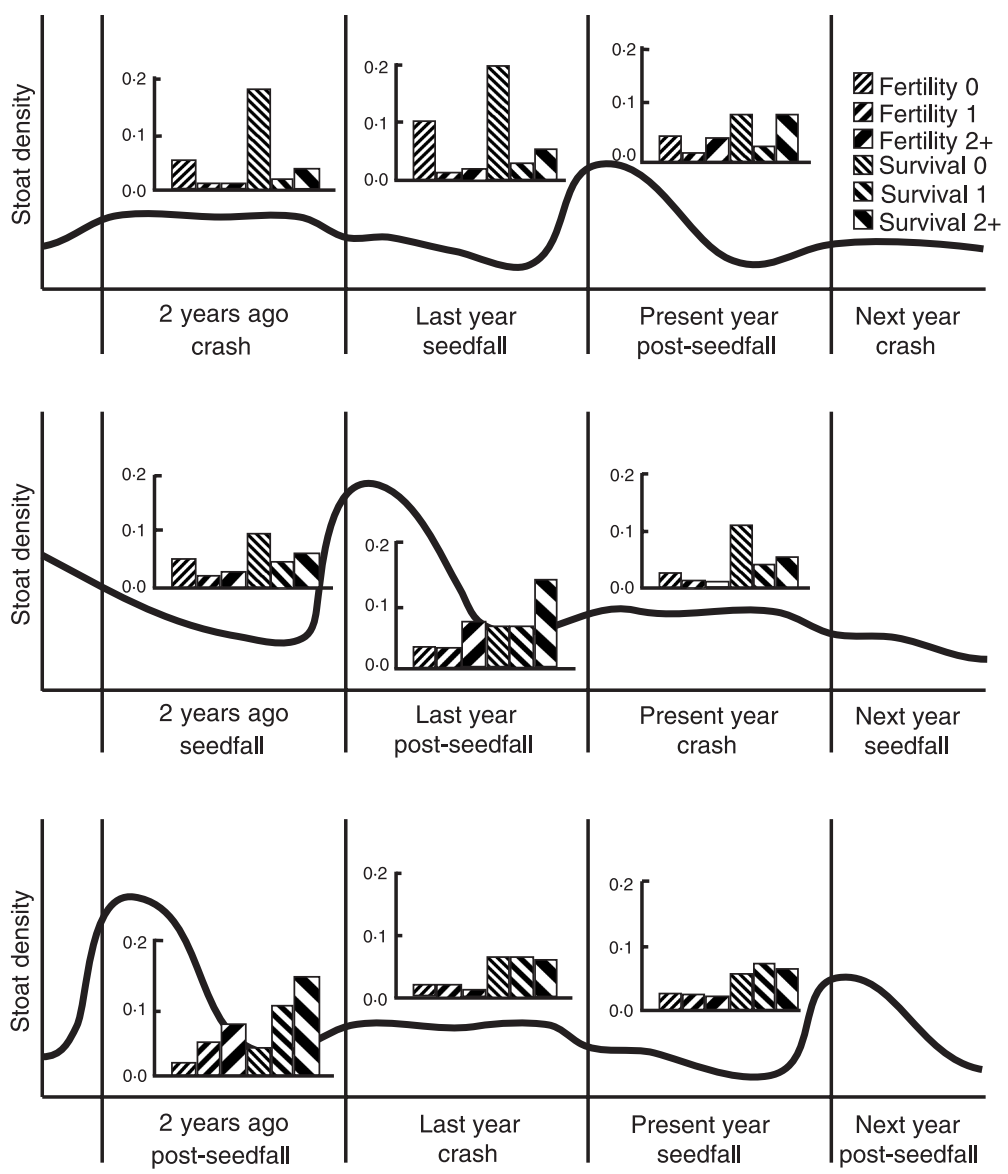

Fig. 3. Lower level elasticities for vital rates in a 3-year cycle for a model stoat population. The bold line shows the general trend of density estimates of stoats for each phase of the cycle (King 2002) to illustrate link between elasticities and actual population dynamics; each row shows the cycle starting at a different phase. The bar graphs on each row show the elasticities for the vital rates for each year of the cycle. Thus, the top row shows the elasticities for vital rates each year that affect $\lambda$ (and population size) in post-seedfall years. As the cycle advances through each year, the elasticities for each year change, showing that in different years, the importance to population growth of the vital rates in each phase change.

(C) 2007 The Authors. Journal compilation (C) 2007 British

Ecological Society, Journal of Animal Ecology, 76, 946-956 age classes. Additionally, the importance of fertility of $0-1$-year-old stoats also increases with the number of years in a cycle. This pattern is most pronounced for cycles when the present year is a post-seedfall year.

\section{Discussion}

Our matrix modelling approach quantifies the variation in the growth rates of stoat populations in New Zealand beech forests among years. The stoat populations we modelled, subject to year-round trapping throughout the beech mast cycle, increased significantly during seedfall and transitional years and decreased during post-seedfall and crash years. Despite substantial uncertainties, the model's results match the observed seasonal density indices for the populations we sampled (King 1983; Fig. 1).

Our analyses produced three important results. First, fluctuations in growth rates of populations of stoats in New Zealand beech forests are primarily driven by (1) the high reproductive success of females born 6 months before a beech mast (i.e. the seedfall year cohort) combined with (2) the low survival and fertility of their young, the females of the post-seedfall cohort. Second, variation in population growth in fluctuating populations of stoats in beech forests is consistently most sensitive to changes in survival rates, not fertility. Finally, the relative contributions from survival and fertility to variation in population growth depend on the year of the cycle and the number of years within a cycle.

Our $\lambda \mathrm{s}$ calculated both for individual matrices and for matrices combined into cycles of different length are consistent with a broad literature across the extensive geographical range of stoats (summarized by King $\&$ Powell 2007) that documents dynamic population irruptions when prey populations increase, frequently followed by local extinction and recolonization. Most wild stoat populations do not exhibit truly cyclic dynamics because prey populations in most places fluctuate randomly or unpredictably. The same is true for the stoat populations that we modelled. Figure 1 shows that intervals between seed falls varied from 2 to 4 years or more (King 1983). Recent evidence suggests that rising temperatures are promoting increased seed production as well as (occasionally) heavy seed falls in successive years (Dilks et al. 2003; Richardson et al. 2005). Consequently, we expect that future estimates of annual rates of population growth in beech forest stoat populations will vary across, and even beyond, the span of $0.58-1.98$ that we calculated from our matrices based on historic data. Of particular concern from a conservation perspective is the possibility of consecutive seedfall years that lead to tremendous growth of stoat populations $(\lambda=1 \cdot 98)$. Thus, our analyses should be considered a baseline for estimating predicted ecosystem-wide changes in community structure following changes in environmental conditions.

Three previous models of stoat population dynamics in beech forests have been based on the parameter values published in King (1983). Our models, using the entire, original data set, generally support them, but with some modifications. Barlow \& Barron (2005) concluded that if culling is done only once during a beech mast cycle, it should concentrate on the post-seedfall year and avoid the crash year. Blackwell et al. (2001) concluded that stoats could control rodent populations during crash and transition years, and implied that releasing rodent populations from predation by stoats between mast years might lead to higher rodent populations after the next mast and, hence, higher stoat populations. Choquenot (2006) explored the interplay between the costs of monitoring environmental cues predicting periods of high stoat density with the benefits of concentrating control efforts at times of highest risk to threatened species.

Our results show clearly that the observed fluctuations in growth rates of stoat populations in New Zealand beech forests are the consequences of a cohort effect. 

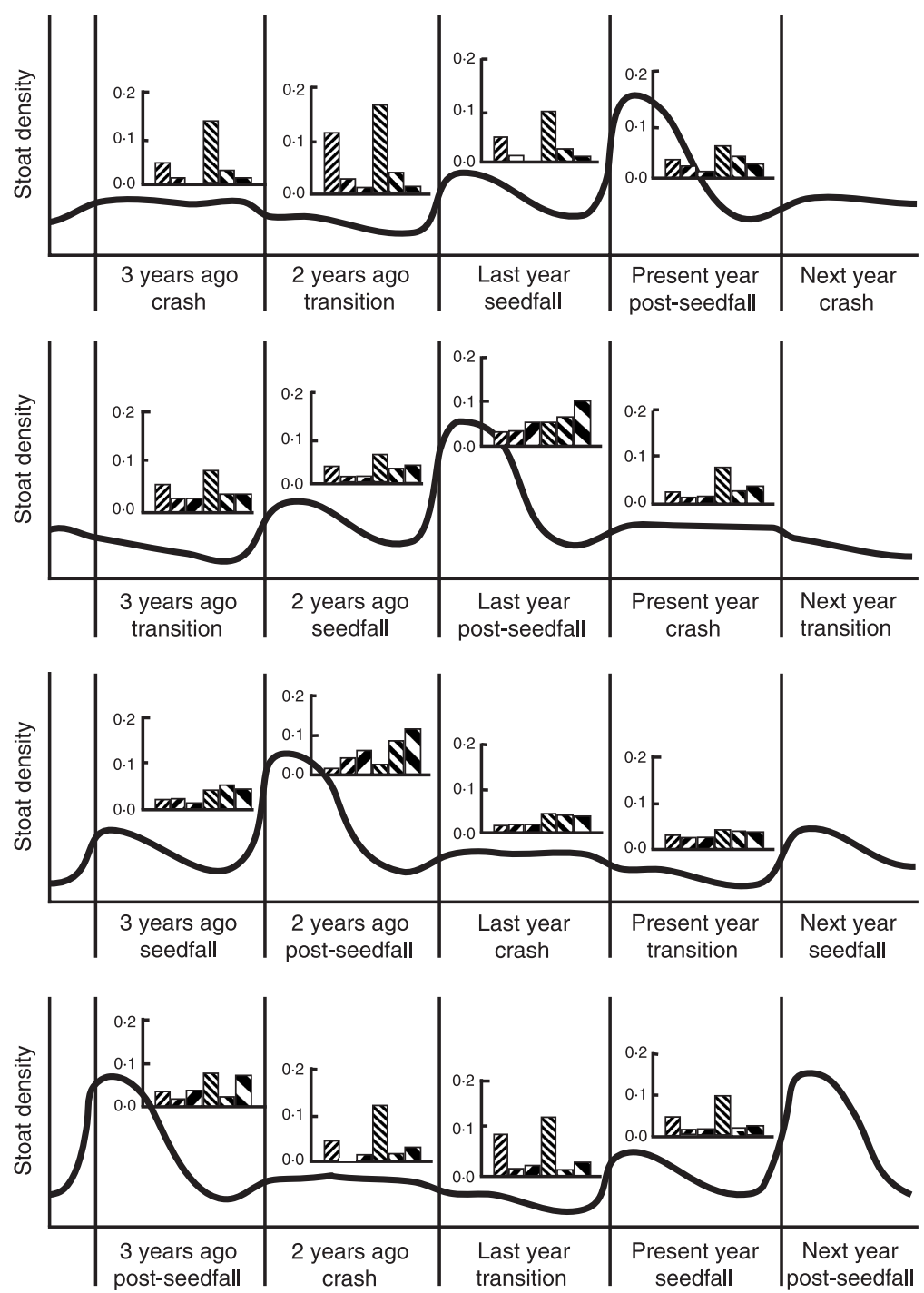

Fig. 4. Lower level elasticities for vital rates in a 4-year cycle for a model stoat population. Description and legend for vital rates as for Fig. 3.

The major population decrease during post-seedfall conditions is caused by the unusually low survival and poor reproduction of first-year stoats, because they reach independence in unusual numbers just as the formerly abundant mice are disappearing (King 2002). The long breeding cycle of stoats requires females to survive not just to, but 1 year past the next increase in food supplies (King et al. 2003b). Summer trapping only brings forward by some months the deaths of many females of the post-seedfall cohort (King \& McMillan 1982) that have very little chance of successfully weaning their first litter at age 1 year. We note, however, that large males born in seedfall years that survive to their first mating season at age 1 year should be dominant over smaller males (Erlinge 1977), may breed with
(C) 2007 The Authors. Journal compilation (C) 2007 British Ecological Society, Journal of Animal Ecology, 76, 946-956 low elasticities for first-year females during post-seedfall years. This result is consistent with those of analyses of comparable population cycles between predators and prey in the northern hemisphere. For example, reproductive values of northern forest owls were consistently higher for individuals born during the phase when prey were not at peak densities (Brommer, Kokko \& Pietiäinen 2000). The cohort effects we quantified are likely to occur in many other systems with cyclic, or widely fluctuating, population dynamics with large variation in growth rates. Examples may include the snowshoe hare Lepus americanus (Erxleben) - Canada lynx Lynx canadensis (Kerr) cycle (Krebs, Boutin \& Bounstra 2001), the possible moose Alces alces (Linnaeus) - wolf Canis lupus (Linnaeus) cycle on Isle Royal (Post et al. 2002), and population cycles for species of the Tetraonidae (Moss \& Watson 2001). Understanding the relationship between environmental conditions and cohort-specific contributions to population growth in these cyclic dynamics is essential both to understand selection of life-history traits and contribute towards management.

Variation in population growth was consistently most sensitive to changes in survival rates, particularly survival of $0-1$-year-old stoats. That sensitivity changed, however, not only with the phase of the cycle but also with the starting year for the cycle and the number of years in the cycle. These results are expected and not new in principle (Caswell \& Trevisan 1994), but are not commonly documented. One expects high reproductive or survival rates to have different effects early vs. late in a cycle. Figures $3-5$ show that populations coming out of the crash phase are predicted to be relatively insensitive to variation in vital rates during any future phase of the cycle. In contrast, populations in most other phases of the cycle appear quite sensitive to survival of $0-1$-year-old in crash years. Thus, targeting control efforts towards the crash year should have major effects on future population growth, including the next population irruption.

The sensitivity of population growth to first-year survival was also reported for stoat populations in Britain (McDonald \& Harris 2002) and appears typical for species with similar life-history strategies (Tuljapurkar \& Caswell 1997). None the less, cross-population generalizations may be meaningful only across similar environments and limiting factors (Coulson et al. 2005). In their study of the dynamics of stoat populations in Britain, McDonald \& Harris (2002) pooled data over a wide geographical area and over several years, masking annual variation in the environment and making direct comparison with our results difficult.

Matrix models have been used widely to evaluate the link between vital rates and variation in population growth. The method assumes, however, that temporal fluctuations in the demographic structure of the population do not have a substantial impact on variation in lambda (Caswell 2000). In many natural populations, however, this assumption is violated. Failure to allow for offspring to future generations than do the females of their own cohort.

The consequence is that females born during peak food availability contribute less to future generations than do females of other cohorts. Figures 2-5 all show 

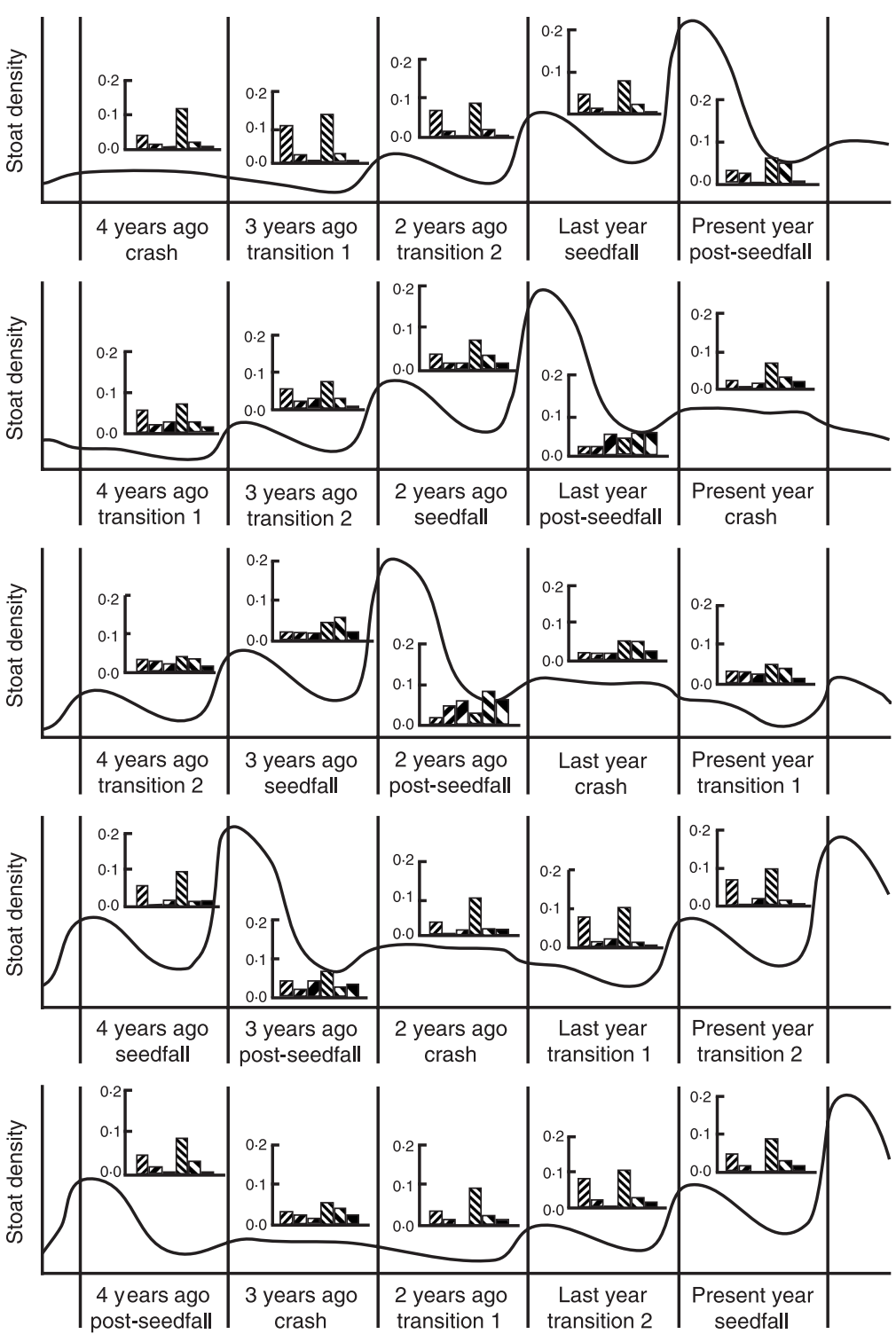

Fig. 5. Lower level elasticities for vital rates in a 5 -year cycle for a model stoat population. Description and legend for vital rates as for Fig. 3.

(C) 2007 The Authors. Journal compilation (C) 2007 British Ecological Society, Journal of Animal Ecology, 76, 946-956 the contribution of covariation between vital rates can therefore result in misleading conclusions when evaluating the differential contributions of vital rates to population growth. For example, Coulson et al. (2005) found that covariation between vital rates in ungulates accounted for up to $50 \%$ of the variation in population growth. In fluctuating populations, this problem can be addressed by linking matrices into cycles (Caswell \& Trevisan 1994).

When we linked matrices into cycles, elasticities for each vital rate in each phase of the cycle changed, in part because the stable age distribution and thus the demographic structure of the population differed with each phase of the cycle. Each phase of the cycle presented the following year with an unstable age distribution, resulting in the observed dependency on whatever the present phase of the cycle is. Vital rates that appear important when viewing the matrix of one phase in isolation, or when comparing two phases not connected into a cycle, may not be important when viewed as part of the entire cycle. For example, results from individual matrices indicated first-year fertility to be exceedingly important during seedfall years and adult survival in post-seedfall years. In contrast, those particular vital rates do not stand out when viewing the entire cycle.

That each phase of the cycle presents the next phase with an unstable age distribution is also critical to understanding $\lambda$ for the whole cycle (Caswell \& Trevisan 1994). Simply multiplying the $\lambda$ s for the matrices, or multiplying the matrices for the cycle and then calculating $\lambda$, produces false values for $\lambda$. For example, multiplying the lambdas for the matrices in a 3-year cycle (and taking the cube root to yield annual growth) produces a value of $0 \cdot 61$, while calculating the $\lambda$ for the product matrix of the three matrices produces a value of 0.95 ; the true $\lambda$ for the 3 -year cycle is 0.85 . Because of the constantly unstable age distribution, the only way to calculate $\lambda$ for a cycle is to multiply the matrix for each phase by the incoming population vector and continuing to multiply year by year by year until enough cycles have been produced to be able to calculate $\lambda$ accurately from the projected population growth. Knowing the matrix for each phase of a cycle is not enough. One must link them to understand their dynamics.

Linking matrices into cycles allowed us to derive three important management recommendations. First, management targeting survival of stoats will consistently be more effective than management targeting fertility. Second, while intensive stoat control during peak years is likely required to minimize predation effects on the native fauna, control measures during postseedfall and crash years (i.e. when stoat populations are at low densities), may be effective in limiting future irruptions of stoats, at least where immigration is minimal. Third, understanding fluctuating populations requires attention to all phases of the fluctuations, each within the context of the other phases. These generalizations are relevant both for conservation of endangered prey populations and for control of pest species in other systems whose populations fluctuate naturally. In such systems, management strategies based on elasticities calculated using mean, invariant vital rates are unlikely to translate into effective management recommendations.

\section{Acknowledgements}

For funding and for data collection we are indebted to the many agencies and people acknowledged in the primary publications describing this material. While working on this project, $\mathrm{H}$. U. Wittmer was partially supported by the Department of Biological Sciences at the University of Waikato. We would particularly like to thank Y. Richard and M. Efford for their insightful comments on matrix models. K. Gross provided reassurance that our matrices were constructed correctly. 
Cohorts and growth rates in fluctuating

\section{populations}

(C) 2007 The Authors Journal compilation (C) 2007 British Ecological Society, Journal of Animal Ecology, 76, 946-956
D. Armstrong, R. Serrouya, P. Zuidema and two anonymous reviewers provided many helpful suggestions on earlier versions of this manuscript.

\section{References}

Albon, S.D., Clutton-Brock, T.H. \& Guiness, F.E. (1987) Early development and population dynamics in red deer. II. Density-independent effects and cohort variation. Journal of Animal Ecology, 56, 69-81.

Allen, R.B. \& Platt, K.H. (1990) Annual seedfall variation in Nothofagus solandri (Fagaceae), Canterbury, New Zealand. Oikos, 57, 199-206.

Barlow, N.D. \& Barron, M.C. (2005) Modelling the dynamics and control of stoats in New Zealand forests. Science for Conservation, 252, 1-40.

Basse, B., McLennan, J.A. \& Wake, G.C. (1999) Analysis of the impact of stoats, Mustela erminea, on northern brown kiwi, Apteryx mantelli, in New Zealand. Wildlife Research, 26, 227-237.

Beckerman, A.P., Benton, T.G., Ranta, E., Kaitala, V. \& Lundberg, P. (2002) Population dynamic consequences of delayed life-history effects. Trends in Ecology and Evolution, 17, 263-269.

Beckerman, A.P., Benton, T.G., Lapsley, C.T. \& Koesters, N. (2003) Talkin' 'bout my generation: environmental variability and cohort effects. American Naturalist, 162, 754767.

Benton, T.G. \& Grant, A. (1999) Elasticity analysis as an important tool in evolutionary and population ecology. Trends in Ecology and Evolution, 14, 467-471.

Blackwell, G.L., Potter, M.A. \& Minot, E.O. (2001) Rodent and predator population dynamics in an eruptive system. Ecological Modelling, 142, 227-245.

Boutin, S., Wauters, L.A., McAdam, A.G., Humphries, M.M., Tosi, G. \& Dhondt, A.A. (2006) Anticipatory reproduction and population growth in seed predators. Science, 314, $1928-1930$.

Brommer, J., Kokko, H. \& Pietiäinen, H. (2000) Reproductive effort and reproductive values in periodic environments. American Naturalist, 155, 454-472.

Case, T.J. (2000) An Illustrated Guide to Theoretical Ecology. Oxford University Press, New York.

Caswell, H. (1989) Matrix Population Models: Construction, Analysis, and Interpretation. Sinauer Associates Inc., Sunderland, MA.

Caswell, H. (2000) Prospective and retrospective perturbation analyses: their roles in conservation biology. Ecology, 81, 619-627.

Caswell, H. \& Trevisan, M.C. (1994) Sensitivity analysis of periodic matrix models. Ecology, 75, 1299-1303.

Caughley, G. (1977) Analysis of Vertebrate Populations. John Wiley \& Sons, London.

Choquenot, D. (2006) Bioeconomic modeling in conservation pest management: effect of stoat control on extinction risk of an indigenous New Zealand Passerine, Mohua ochrocephala. Conservation Biology, 20, 480-489.

Choquenot, D. \& Ruscoe, W.A. (2000) Mouse population eruptions in New Zealand forests; the role of population density and seedfall. Journal of Animal Ecology, 69, 10581070.

Coulson, T., Gaillard, J.-M. \& Festa-Bianchet, M. (2005) Decomposing the variation in population growth into contributions from multiple demographic rates. Journal of Animal Ecology, 74, 789-801.

De Kroon, H., van Groenendael, J. \& Ehrlén, J. (2000) Elasticities: a review of methods and model limitations. Ecology, 81, 607-618.

Dilks, P., Willans, M., Pryde, M. \& Fraser, I. (2003) Large scale stoat control to protect mohua (Mohoua ochrocephala) and kaka (Nestor meridionalis) in the Eglinton Valley, Fiordland, New Zealand. New Zealand Journal of Ecology, 27, 1-9.

Efron, B. \& Tibshirani, R. (1993) An Introduction to the Bootstrap. Chapman \& Hall, New York.

Erlinge, S. (1977) Agonistic behaviour and dominance in stoats (Mustela erminea L.). Zeitschrift für Tierpsychologie, 44, 375-388.

Hood, G.M. (2005) Pop Tools, Version 2·6·6. Available on the internet. http://www.cse.csiro.au/poptools (accessed May 2006).

King, C.M. (1980) Field experiments on the trapping of stoats (Mustela erminea). New Zealand Journal of Zoology, 7, 261-266.

King, C.M. (1981) The reproductive tactics of the stoat (Mustela erminea) in New Zealand forests. Proceedings of the First Worldwide Furbearer Conference (eds J.A. Chapman \& D. Pursley), pp. 443-468. Worldwide Furbearer Conference Inc., Frostburg, MD.

King, C.M. (1983) The relationships between beech (Nothofagus sp.) seedfall and populations of mice (Mus musculus), and the demographic and dietary responses of stoats (Mustela erminea), in three New Zealand forests. Journal of Animal Ecology, 52, 141-166.

King, C.M. (2002) Cohort variation in the life-history parameters of stoats (Mustela erminea) in relation to fluctuating food resources: a challenge to boreal ecologists. Acta Theriologica, 47, 225-244.

King, C.M. \& McMillan, C.D. (1982) Population structure and dispersal of peak year cohorts of stoats (Mustela erminea) in two New Zealand forests, with special reference to control. New Zealand Journal of Ecology, 5, 59-66.

King, C.M. \& Moody, J.E. (1982) The biology of the stoat (Mustela erminea) in the national parks of New Zealand. New Zealand Journal of Zoology, 9, 49-144.

King, C.M. \& Powell, R.A. (2007) The Natural History of Weasels and Stoats: Ecology, Behaviour, and Management. Oxford University Press, New York.

King, C.M., Davis, S.A., Purdey, D.C. \& Lawrence, B. (2003a) Capture probability and heterogeneity of trap response in stoats, Mustela erminea. Wildlife Research, 30, 611619.

King, C.M., White, P.C.L., Purdey, D.C. \& Lawrence, B. (2003b) Matching productivity to resource availability in a small predator, the stoat (Mustela erminea). Canadian Journal of Zoology, 81, 662-669.

Krebs, C.J., Boutin, S. \& Boonstra, R., eds. (2001) Ecosystem Dynamics of the Boreal Forest: the Kluane Project. Oxford University Press, New York.

Lindstrom, J. (1999) Early development and fitness in birds and mammals. Trends in Ecology and Evolution, 14, 343-348.

McDonald, R.A. \& Harris, S. (2002) Population biology of stoats Mustela erminea and weasels Mustela nivalis on game estates in Great Britain. Journal of Applied Ecology, 39, 793-805.

Mills, L.S., Doak, D.F. \& Wisdom, M.J. (1999) Reliability of conservation actions based on elasticity analysis of matrix models. Conservation Biology, 13, 815-829.

Moss, R. \& Watson, A. (2001) Population cycles in birds of the grouse family (Tetraonidae). Advances in Ecological Research, 31, 53-110.

Murphy, E.C. \& Dowding, J.E. (1994) Range and diet of stoats (Mustela erminea) in a New Zealand beech forest. New Zealand Journal of Ecology, 18, 11-18.

O'Donnell, C.F.J. \& Phillipson, S.M. (1996) Predicting the incidence of mohua predation from the seedfall, mouse, and predator fluctuations in beech forests. New Zealand Journal of Zoology, 23, 287-293.

Pfister, C.A. \& Stevens, F.R. (2003) Individual variation and environmental stochasticity: implications for matrix model predictions. Ecology, 84, 496-510. 


\section{6}

H.U. Wittmer,

R. A. Powell \&

C.M. King
Post, E., Stenseth, N.C., Peterson, R.O., Vucetich, J.A. \& Ellis, A.M. (2002) Phase dependence and population cycles in a large-mammal predator-prey system. Ecology, 83, 2997-3002.

Powell, R.A. \& King, C.M. (1997) Variation in body size, sexual dimorphism and age-specific survival in stoats, Mustela erminea (Mammalia: Carnivora), with fluctuating food supplies. Biological Journal of the Linnean Society, 62, 165-194.

Pryde, M.A., O'Donnell, C.F.J. \& Barker, R.J. (2005) Factors influencing survival and long-term population viability of New Zealand long-tailed bats (Chalinolobus tuberculatus): Implications for conservation. Biological Conservation, 126, 175-185.

Richardson, S.J., Allen, R.B., Whitehead, D., Carswell, F.E., Ruscoe, W.A. \& Platt, K.H. (2005) Climate and net carbon availability determine temporal patterns of seed production by Nothofagus. Ecology, 86, 972-981.

Ruscoe, W.A. \& Murphy, E.C. (2005) House mouse. The Handbook of New Zealand Mammals, 2nd edn (ed. C.M. King), pp. 204-221. Oxford University Press, Melbourne.
Shea, K. \& Kelly, D. (1998) Estimating biocontrol agent impact with matrix models: Carduus nutans. New Zealand. Ecological Applications, 8, 824-832.

Tuljapurkar, S. \& Caswell, H. (1997) Structured Population Models in Marine, Terrestrial, and Freshwater Systems. Chapman \& Hall, New York.

White, P.C.L. \& King, C.M. (2006) Predation on native birds in New Zealand beech forests: the role of functional relationships between stoats and rodents. Ibis, 148, 765771.

Wilson, P.R., Karl, B.J., Toft, R.J., Beggs, J.R. \& Taylor, R.H. (1998) The role of introduced predators and competitors in the decline of Kaka (Nestor meridionalis) populations in New Zealand. Biological Conservation, 83, 175-185.

Wisdom, M.L. \& Mills, L.S. (1997) Using sensitivity analysis to guide population recovery: Prairie chicken as an example. Journal of Wildlife Management, 61, 302-312.

Received 2 March 2007; accepted 16 May 2007

Handling Editor: Piran White 